\title{
Evolution of film morphology in polymer solar cells based on rough electrode substrates
}

Xianyu Jia ${ }^{\mathrm{a}}$, Ziyang $\mathrm{Hu}^{\mathrm{a}, *}$, Suzhen Luan ${ }^{\mathrm{b}}$, Jie Xu ${ }^{\mathrm{a}}$, Houcheng Zhang ${ }^{\mathrm{a}}$, Jing Zhang ${ }^{\mathrm{a}}$, Yuejin Zhu ${ }^{\mathrm{a}}$

${ }^{a}$ Department of Microelectronic Science and Engineering, Ningbo Collabrative Innovation Center of Nonlinear Harzard System of Ocean and Atmosphere, Ningbo University, Ningbo 315211, China

${ }^{\mathrm{b}}$ School of Electronic Engineering, Xidian University, Xi'an 710071, China

\begin{abstract}
Periodic and random nanostructures as light-trapping management are extremely
promising strategies to largely enhance light harvesting and efficiency of solar cell. However, solution-processed films deposited on nanostructured substrates often bring out uncontrollable morphology and lead to deficient interface. In this work, evolved multilayer film morphologies based on nanostructured electrode substrates were investigated in polymer solar cells. It was demonstrated that the different degree of rough front electrodes would significantly influence the morphologies of the following hole transport layer, active layer, and rear electrode layer. The morphological and optical properties of each layer on different rough front electrodes were compared in order to demonstrate the possibly evolved mechanism. A double light-trapping structure with a nano-textured front electrode and micro-textured rear electrode was realized to obtain the high-performance device.
\end{abstract}

Keywords: Polymer solar cell; Morphological evolution; Surface roughness; Light scattering

\section{Introduction}

*E-mail addresses: huziyang@nbu.edu.cn 
Bulk heterojunction polymer solar cell (PSC) is a promising photovoltaic production for clean and renewable energy sources due to its superior properties such as mechanical flexibility, low weight, and large-area production [1-4]. Power conversion efficiencies (PCEs) of state-of-the-art organic solar cells have been dramatically improved, combination with sophisticated control over electronic structures and the morphology of photoactive materials as well as interface modification for efficiency charge collection in the past decade [5-6]. Further enhancement in the efficiency is urgently required for single-junction PSCs towards practical applications. One of the major hurdles of these organic materials towards higher PCEs is the low carrier mobility which imposes limits on the thickness of the photoactive layers to facilitate concurrently efficient carrier extraction and high optical absorption [7-9]. Furthermore, PSCs possess a multilayer structure consisting of layers with different complex refractive indexes, the light absorption at each layer and the reflection at interfaces prevent more light from entering the photoactive layer, thus resulting in low external quantum efficiency (EQE) and PCE. The optical manipulation has introduced as a popular strategy to capture more solar radiation into a constrained photoactive layer with efficient charge extraction and without compromising PCE [10-11]. In addition, increasing absorption also contribute to reduce the photoactive layer thickness, which impacts production costs and enables the use of less absorber materials.

From the simple geometrical optics of view, light trapping exploits the effect of total internal reflection by roughening the incident interface and randomizing the light propagation direction inside the photoactive materials [12-17]. When highly ordered (periodic) and random nanostructures are incorporated into PSCs, the optical path length of the incident light increase significantly due to light scattering on the textured surfaces at oblique angles and the enhanced 
total internal reflection at the interfaces within the cells. Recent theoretical studies have shown that absorption enhancement factors with appropriately integrated nanostructures are expected to boost absorption in organic solar cells [18-19]. Even though the issue whether periodic structures can outperform random textures is still entangled, theoretical calculations predict higher absorption enhancements at specific wavelength bands for periodic architectures, which can be adjusted by the dimension of the periodic structure [20-21]. The random nanostructure is potentially advantageous for light trapping in the broadband response covering the full solar spectral ranges and the compatibility for low-cost manufacturing without sophisticated and expensive fabrication technologies. Currently, many attempts are hindered for the practical adoption due to the necessity to precisely engineer the nanoscale structures at appropriate interfaces [22-23]. As previous reported, nanostructured transparent conducting oxide (TCO) layers are used as effective light-scattering structures in prolonging the optical path within the active layers, an enhanced short-circuit current density $\left(J_{s c}\right)$ was always obtained [24-26]. However, solution-processing nanoscale thick layers on topographical surfaces of TCO films can result in overfilling and voids formed in the subsequently deposited layers of the solar cells [26-27]. Furthermore, both the leakage channels formed by the voids and the anisotropic thickness of active layer decrease the fill factor $(\mathrm{FF})$ and open circuit voltage $\left(V_{o c}\right)$ of the cells, and then depress their efficiency [27-28]. In previous reports [13-14, 28], periodic nanostructures via adjusting the dimensional size were readily incorporated into PSCs to coat a conformal polymer film. However, so far, few reports focus on the evolved morphology of each layer on random nanostructures in PSCs.

In this contribution, we emphasized the evolved multilayer film morphologies on rough 
electrode substrates with different root mean square (RMS) surface roughness. It was found that different degree of rough front electrodes would result in the under layers with different dimensional morphology. Double light-trapping PSCs consisting of nano-textured front electrode substrates, and micro-textured rear electrodes were realized. The dependence of the evolved morphologies correlating with the optical, electrical and surface properties on device performance was addressed.

\section{Experimental section}

The commercial ZnO:Al(AZO:1000nm) glass substrates were wet chemical etched using a $\mathrm{HCl}$ solution (concentration: $0.5 \%)$ for different time $(0 \mathrm{~s}, 10 \mathrm{~s}, 20 \mathrm{~s}, 30 \mathrm{~s}, 40 \mathrm{~s})$. The rough surfaces with different degree were obtained. The etched substrates were thoroughly cleaned and then dried. After the substrates were treated by UV-Ozone for $10 \mathrm{~min}$, a buffer layer of poly(3,4-ethylenedioxythiophene):poly(styrenesulfonate) (PEDOT:PSS) was spin coated on them, and then baked at $150{ }^{\circ} \mathrm{C}$ for $30 \mathrm{~min}$ to remove moisture. A blend solution of poly(3-hexylthiophene) (P3HT) and [6,6]-phenyl- $\mathrm{C}_{61}$-butyric acid methyl ester (PCBM) was spin coated at $600 \mathrm{rpm}$ for $10 \mathrm{~s}$ onto the PEDOT:PSS coated substrates. The thickness of the

P3HT:PCBM layer is about $100 \mathrm{~nm}$. Finally, the solar cell devices were completed by depositing $0.8 \mathrm{~nm} \mathrm{LiF}$ and $100 \mathrm{~nm} \mathrm{Al}$ as cathode. The absorption and transmission spectra were characterized using a Varian Cary 5000 UV-Vis-NIR spectrophotometer with an integrating sphere. The surface morphologies of all films were characterized by atomic force microscopy (AFM, Bruker Multimode 8) in tapping mode and scanning electron microscope (SEM, Hitachi SU-70). All the current-voltage $(J-V)$ curves were characterized using a Keithley 4200 source measure unit in air 
under $100 \mathrm{~mW} / \mathrm{cm}^{2} \mathrm{AM} 1.5$ simulated light measurement.

\section{Results and discussion}

In order to obtain the different morphology, AZO substrates with different surface roughness were intended to build by $\mathrm{HCl}$ etching for different time. The evolved surface morphologies of the AZO films were visualized by the AFM as shown in Fig.1 (a-c). When the AZO films were textured for $10 \mathrm{~s}$, particle clusters remove on the surface of the film while holes were introduced as shown in Fig. 1 (b). With an increase in etching time, the number of holes increased, with a subsequent increase in the diameter of the holes. For the $30 \mathrm{~s}$ etching sample the size of holes even grew up to a few micrometers as shown in Fig. 1 (c). At the same time, the edges of the holes became smooth owing to the isotropic nature of wet etching, and the shape of the holes gradually become crater-like. The better lateral uniformity of the surface textures was also obtained as shown in Fig. 1(c). However, for $40 \mathrm{~s}$, further reaction etched the AZO film in excess, which results in the re-etching of the formed edge and bottom side of the craters. Nevertheless, with increasing the etching time, AZO substrates with different surface morphologies were obtained.

From the surface height-profile of Fig. 1(d), we see that the nonetching AZO surface has a maximum peak-to-valley height of only $50 \mathrm{~nm}$. After etching, the randomly sized textured surfaces present an increased peak-to-valley height with the maximum up to $500 \mathrm{~nm}$. These surface morphologies of AZO films with the different etching time can reflect the various degrees of surface roughness. When the etching time was increased from 0 to $40 \mathrm{~s}$, the RMS roughness was increased from 10.5 to $98.2 \mathrm{~nm}$. The RMS roughness of all films was collected in Table 1 . These nonetching AZO films showed a low sheet resistance of $\sim 10 \Omega / \square$ with a thickness of 
around $1 \mu \mathrm{m}$. After $20 \mathrm{~s}$ of etching, the sheet resistance increased to $\sim 13.8 \Omega / \square$. After the etching for $40 \mathrm{~s}$, the corresponding sheet resistance gradually increased to $\sim 17.5 \Omega / \square$, due to the reduced film thickness. Using the thickness value obtained from SEM, it follows that the AZO etching rates in $0.5 \% \mathrm{HCl}$ are approximately the same $(10-15 \mathrm{~nm} / \mathrm{s})$. This explains why the etching sequence seems to have little effect on the change of the sheet resistance value.

Fig. 2 (a) shows the haze spectrum of AZO films under various etching time. In contrast to the electrical performance, the optical properties are quite sensitive to the etching process and the surface morphology. Before texturing, the nonetching AZO substrate shows a high visible transmission value fluctuating around $83 \%$ but virtually no scattering capabilities with a haze value of approximately $5 \%$. AZO texturing resulted in a high haze value in despite of the short etching time, while maintaining similar optical transmission. With respect to the etching for $10 \mathrm{~s}$, the AZO film substrate yields a haze value of $58 \%$ at $500 \mathrm{~nm}$ wavelength. A maximum haze value of $75 \%$ is obtained after the etching for $30 \mathrm{~s}$. Further etching above $40 \mathrm{~s}$ gradually deteriorates the haze value by up to $10 \%$. As a result, the corresponding haze value initially increases, then reaches a maximum, and then decreases again for etching times of more than $40 \mathrm{~s}$. Therefore, around 20 or $30 \mathrm{~s}$ of etching is enough to achieve an optimized the features and thus enhance the haze value for good scattering, and further etching seems not to improve much anymore.

For a quantitative characterization of the evolved morphologies and the dependence of light scattering effect, the measured information on the surface depth-profile of the texture features is then extracted from AFM as shown in Fig. 3. For the nonetching AZO film, the texture has a very narrow depth distribution $(0-70 \mathrm{~nm})$, while the etched AZO films have a gradually increased height distribution (up to $500 \mathrm{~nm}$ ) increasing with the etching time as shown in Fig. 3. It is well 
known that a broad surface depth distribution is beneficial for light trapping in thin-film solar cells for a wide range of wavelengths [29-30]. However, we should bear in mind that even the $10 \mathrm{~s}$ etched sample with a maximum depth distribution center of $\sim 75 \mathrm{~nm}$, a high haze value was also obtained as indicated in Fig. 2(a). We suggest that the construction of PSCs using the differently etched-AZO films can provide information about dependence of the surface morphology for photovoltaic performance with only minor influences from electronic properties of AZO films.

The common PEDOT:PSS layer and P3HT:PCBM layer are chosen as the hole transport layer and active layer, respectively, because there are the most widely investigated system in the field of PSCs. The evolved multilayer film morphologies on the represented surface of the etched AZO for $10 \mathrm{~s}$ and $30 \mathrm{~s}$ were investigated, respectively. The water soluble PEDOT:PSS films were subjecting to different degrees of surface modification by varying the spinning time. As can be seen from the AFM images in Fig. 1(b, c), the surfaces of the etched AZO films consisted of very sharp edges and tips of different size. After the PEDOT:PSS covered, most of the tips disappeared and the sharp edges were smoothed, owing to the smoothening effect of continual PEDOT:PSS film as shown in Fig. 4(a, c). The small holes (etched for $10 \mathrm{~s}$ ) or craters (etched for $30 \mathrm{~s}$ ) are filled with PEDOT:PSS, and the surface roughness begin to reduce, while the large holes or craters are still retained as shown in Fig. 4(a, c). This may result in the deposition of PEDOT:PSS films of different thicknesses on the rough AZO substrates. However, we did not find any loss in total transmittance due to the low absorption of the PEDOT:PSS films, and a high haze value was still retained as shown in Fig. 2(b).

When the active layers again covered on the PEDOT:PSS films, they further smoothed the surface features of the films, decreasing their surface RMS roughness. As can be seen from the 
AFM images in Fig. 4(b) for the $10 \mathrm{~s}$ etching sample, the topography of the active layer did not follow the underlying morphology of the buffer layer and presents the roughness just like the active layer was coated on the flat substrate as shown in table 1S. Because the thickness and spin speed of active layer are thicker and slower than those of the PEDOT:PSS buffer layer, respectively, the morphology of the active layer is independent of the modified textured AZO film etched for $10 \mathrm{~s}$. However, the active layer covered on the surface of the $30 \mathrm{~s}$ etched AZO substrate gets rid of the crests but still keeps the macroscopically morphology with clear big craters as shown in Fig. 4(d). We suppose that the topographies of the same active layers transferred on the different surface may be different. According to the evolved surface height-profile from AZO films to P3HT:PCBM films in Fig. 5, it can be seem that the surface height distributions gradually reduce and the curve profiles also gradually become smooth. No sharp tips are retained. Most of the tips from the textured AZO has been smoothened by the PEDOT:PSS film and further removed by the following P3HT:PCBM layers. Once the small and continual valleys between the tips were covered, they then dispersed instead of accumulating on the smoothened surfaces. Generally, using vapor phase deposition processing, the following formed films always conformally transfer on the rough surface in organic solar cells or inorganic thin film solar cells $[21,28,31]$. However, the solution-processing deposited films may tend to smooth the rough surface due to the liquid mobility of solution especially using the coating technique [20]. Cross-sectional SEM images of the completed OPVs based on textured AZO electrodes are shown in Fig. 6(a, c). It is found that the different rear electrode morphologies were clearly presented for the $10 \mathrm{~s}$ and $30 \mathrm{~s}$ etched AZO substrates. For the $10 \mathrm{~s}$ etched AZO substrate, the almost flat surface of $\mathrm{Al}$ electrode was realized, while a fluctuant surface within a micrometer 
range was presented for the $30 \mathrm{~s}$ etched AZO substrate. However, we still believe that the cathode deposited completely on the organic layer for all PSCs. According to the above discussion, the possible evolved multilayer topographies base on the two specified rough electrodes were depicted, as shown in Fig. 6(b,d). Also, the schematic sketches of different light paths in the two devices were also introduced. The reason of different light paths will discuss below. The respective thickness of the layers in the drawing is proportional to the practical devices.

We investigated the dependence of the device performance on the surface morphology of AZO. As shown in Fig. 7, the general trend for PCE, FF, $J_{s c}$, and $V_{o c}$ of PSCs are statistical summarized as a function of etching time. The devices fabricated on the textured substrates without PEDOT:PSS film completely failed to show photovoltaic behavior due to large number of shunts. Compare with the devices with nonetching AZO films, the devices with the textured substrates show a slight reduce in $V_{o c}$. The texturing process may lead to the formation of shunt path and current leakage at the rough interface, resulting in a decrease in $V_{o c}$. Regarding the FFs, a long etching time ( $40 \mathrm{~s})$ resulted in a significant degradation with respect to the values of the other counterparts. The over etching may lead to serious leakage current and reduce the shunt resistance, so FF is reduced. Increasing the etching time leads to improve in the $J_{s c}$ values; however, when the etching time was increased to $40 \mathrm{~s}, J_{s c}$ begins to degrade. The $J_{s c}$ of the device consisting of $30 \mathrm{~s}$ etched AZO films is $\sim 12.06 \mathrm{~mA} \mathrm{~cm}^{-2}$, and the value is more than $\sim 21 \%$ higher than that $(\sim 9.95$ $\mathrm{mA} \mathrm{cm}{ }^{-2}$ ) of the device with the nonetching film.

The results show that the PCE enhancement is mainly a consequence of an increase in $J_{s c}$. Photocurrent generation is principally governed by three major factors. These are the number of absorbed photons and carriers generated by charge separation at the donor and acceptor interface, 
and the charge-collection efficiency [32]. When the incident light first reaches at the textured electrode, it was scattered. The scattering light crosses the active layer and was first absorbed. For the $10 \mathrm{~s}$ etched device, the passed light facing the mirror of the flat $\mathrm{Al}$ electrode reflected into the active layer and reabsorbed by the active layer as presented in Fig. 6(b). For the $30 \mathrm{~s}$ etched device, the passed light reach the structured rear electrode, where scattering and diffusely reflection on the curved surface occur, as shown in Fig. 7(d). Thus, the light crosses the absorber layer at a larger angle on the way back, elongating the path for absorption. We suppose the two different rear reflections from the different surface depth distribution of the active layers. In Fig. 8 (a), for the 10 s etching device, the evolved surface height of the active layer was similar to that of the nonetching AZO films (indicted in Fig. 3), and the haze value is negligible (indicted in Fig. 2). In Fig.8 (b), however, for the $30 \mathrm{~s}$ etching device, the evolved surface height of the active layer still retained up to $150 \mathrm{~nm}$. Based on the conclusion of from Fig. 3, the scatter effect is still existed. Hence the light escaped from the active layer was reduced for the $30 \mathrm{~s}$ sample. Just like as shown in Fig. 6(d), there will be scattering as well as reflection of light at the cathode due to the corrugated interface between the active layer and the cathode [33]. It is noticed that the curved rear electrode presents about micrometer feature size, so we suppose that diffuse reflection is more effective for long wavelength. As discussed before, the textured front surface is effective for short wavelength scattering. Hence, we did not find a great increase in $J_{s c}$ from the $10 \mathrm{~s}$ device to the 30 $\mathrm{s}$ device due to the absorption of the active layer focus on wavelength less than $650 \mathrm{~nm}$.

The light-scattering effect on contributing absorption of active layer coated on the different substrates are also measured and depicted in Fig. 9(a). Compared with the nonetcing sample, the absorption of the textured samples was averagely increased. The absorption of the $40 \mathrm{~s}$ sample 
presents the averagely reduced transmittance and enhanced absorption for excellent light scattering effect. We should keep in mind that the measurement of the samples without the back reflected $\mathrm{Al}$ cathode. Generally, the total reflection spectra of the completed device can represent the real absorption of the active layer if we ignore the low absorption of other layers. So, the reflection spectrum of the completed devices was characterized in order to further understand the effect of light scatter. Due to the back reflected Al cathode, the scattered light induced by the textured films can multiple pass through the absorption layer, leading to increased path length and enhanced absorption. In Fig. 9 (b), the total reflection curve for the textured cells was averagely reduced, suggesting that less light escapes the cells after reflection. For the $20 \mathrm{~s}, 30 \mathrm{~s}$ and $40 \mathrm{~s}$ etching device, there is a lower reflection in the long waveband $(\lambda>550 \mathrm{~nm})$, which demonstrates the enhanced absorption in this waveband. The corrugated interface may induce diffuse reflection as discussed above. These results strongly support the depicted light paths as shown in Fig. (6). The waved total reflection spectrum may be caused by light interference, so combination with other methods such as using optical spacers and antireflection films are supposed to further reduce the light reflection [34-35].

We think that the fluctuant electrodes allow distributed conducting pathways for low-mobility carriers, offering a highly scaffolded cell architecture, which may arguably contribute to the germinate separation and carrier collection [26, 36]. This was demonstrated by the average enhancement of the EQE values as shown in Fig. 9(c). It should be mentioned that the photovoltaic performance in PSCs is not only dependent on the surface roughness, but also on many other surface structure factors such as shape [25-26]. This is probably the reason why the correlation between the roughness RMS value and photovoltaic performance is not perfect. 
However, we clearly show that not only electronic and optical properties but also surface morphology control of the electrode is important for obtaining high-performing PSCs. As a result, it was confirmed that the nano-textured front electrode substrates, the submicron-textured active layer, and the micro-textured rear electrode can effectively improve the photovoltaic performance by efficient light-trapping effect.

Finally, in PSCs, the front texture of the active layer is determined by the textured electrode, but the rear texture is not intentionally controlled. In inorganic thin film solar cells, the front and the rear texture can be determined by the textured electrode. Because of the conformal growth of solid films, the surface morphology of the substrate can be replicated on the film surface to some extent [33]. Thus, surface texturing is inevitably introduced on the surfaces of the inorganic solid films during the process of the deposition [37]. However, surface texturing is not readily introduced on the surfaces of the organic solid films when the solution process was applied to deposit films on such textured substrates. Therefore, the contributions of the front and rear textures to light trapping should be different, because the optical behaviors at the front electrode/organic interface and the organic/reflector interface combining with the scalable surface morphologies are different. From this point of view, the optimized texture shape is not necessarily the same for the front and rear surfaces. Therefore, to maximize the light-trapping properties of front and rear textures, their morphologies should be controlled independently.

\section{Conclusions}

In conclusion, we fabricated and characterized PSCs with varied front textures to address their contributions to light trapping systematically. The morphological and optical properties of each 
layer coated on the rough front electrode were account for the device performance. Two different morphologies of rear electrodes were observed, and the micro-textured rear electrode may further provide additional light absorption. A structure with a nano-textured front electrode and micro-textured rear electrode was proposed to obtain the high-performance device through double light-trapping effect. This work not only revealed the in-depth understanding of evolved morphology on rough surface, but also demonstrated the implementing geometrical light trapping by front and rear textured random surfaces. These results are generic and can be applied to any type of optoelectronic device.

\section{Acknowledgements}

This work was supported by the National Science Foundation of China (Grant Nos. 11304170, 11374168, and 51302137), the Natural Science Foundation of Zhejiang Province (Grant No. LQ13F050007), and the Foundation of Zhejiang Educational Commission (Grant Nos. Y201326905, Y201430419). The authors would like to thank the sponsor by K.C. Wong Magna Fund in Ningbo University and the China Scholarship Council (CSC).

\section{References}

[1] B. Kippelen, J.L. Bredas, Organic photovoltaics, Energy Environ. Sci. 2 (2009) 251-261.

[2] R. Søndergaard, M. Hösel, D. Angmo, T.T.L. Olsen, F.C. Krebs, Roll-to-roll fabrication of polymer solar cells, Mater. Today 15 (2012) 36-49.

[3] C.E. Small, S. Chen, J. Subbiah, C.M. Amb, S.W. Tsang, T.H. Lai, J.R. Reynolds, F. So, High-efficiency inverted dithienogermole-thienopyrrolodione-based polymer solar cells, Nat. 
Photonics 6 (2012) 115-120.

[4] S. Lizin, J. Leroy, C. Delvenne, M. Dijk, E.D. Schepper, S.V. Passel, A patent landscape analysis for organic photovoltaic solar cells: Identifying the technology's development phase, Renew. Energ. 57 (2013) 5-11.

[5] J.D. Chen, C. Cui, Y.Q. Li, L. Zhou, Q.D. Ou, C. Li, Y. Li, J.X. Tang, Single-junction polymer solar cells exceeding 10\% power conversion efficiency, Adv. Mater. 27 (2015) 1035-1041.

[6] C.C. Chen, W.H. Chang, K. Yoshimura, K. Ohya, J. You, J. Gao, Z. Hong, Y. Yang, An efficient triple-junction polymer solar cell having a power conversion efficiency exceeding $11 \%$, Adv. Mater. 26 (2014) 5670-5677.

[7] Z. Hu, J. Zhang, L. Huang, J. Sun, T. Zhang, H. He, J. Zhang, H. Zhang, Y. Zhu, Natural drying effect on active layer for achieving high performance in polymer solar cells, Renew. Energ. 74 (2015) 11-17.

[8] P.E. Shaw, A. Ruseckas, I.D.W. Samuel, Exciton diffusion measurements in poly (3-hexylthiophene), Adv. Mater. 20 (2008) 3516-3520.

[9] X. Hu, C. Yi, M. Wang, C.H. Hsu, S. Liu, K. Zhang, C. Zhong,F. Huang, X. Gong, Y. Cao, High-performance inverted organic photovoltaics with over $1-\mu \mathrm{m}$ thick active layers, Adv. Energy Mater. 4 (2014) 1400378-1400385.

[10] D.H. Ko, J.R. Tumbleston, A. Gadisa, M. Aryal, Y. Liu, R. Lopez, E,T. Samulski, Light-trapping nano-structures in organic photovoltaic cells, J. Mater. Chem. 21 (2011) $16293-16303$.

[11] Z. Tang, W. Tress, O. Inganäs. Light trapping in thin film organic solar cells, Mater. Today17 (2014) 389-396. 
[12] P.P. Cheng, L. Zhou, J.A. Li, Y.Q. Li, S.T. Lee, J.X. Tang, Light trapping enhancement of inverted polymer solar cells with a nanostructured scattering rear electrode, Org. Electron. 14 (2013) 2158-2163.

[13] J.Y. Chen, M.H. Yu, C.Y. Chang, Y.H. Chao, K.W. Sun, C.S. Hsu, Enhanced performance of organic thin film solar cells using electrodes with nanoimprinted light-diffraction and light-diffusion structures, ACS Appl. Mater. Interfaces 6 (2014) 6164-6169.

[14] K.S. Nalwa, J.M. Park, K.M. Ho, S. Chaudhary, On realizing higher efficiency polymer solar cells using a textured substrate platform, Adv. Mater. 23 (2011) 112-116.

[15] Z. Chen, X. Zhang, J. Fang, J. Liang, X. Liang, J. Sun, D. Zhang, N. Wang, H. Zhao, X. Chen, Q. Huang, C. Wei, Y. Zhao, Enhancement in electrical performance of thin-film silicon solar cells based on a micro- and nano-textured zinc oxide electrodes, Appl. Energy 135 (2014) 158-164.

[16] C. Cho, H. Kim, S. Jeong, S.W. Baek, J.W. Seo, D. Han, K. Kim, Y.K. Park, S. Yoo, J.Y. Lee, Random and V-groove texturing for efficient light trapping in organic photovoltaic cells, Sol. Energy Mater. Sol. Cells 115 (2013) 36-41.

[17] Z. Hu, J. Zhang, Y. Zhao, Efficient polymer solar cells based on light-trapping transparent electrodes, Appl. Phys. Lett. 100 (2012) 103303-103306.

[18] Z. Yu, A. Raman, S. Fan, Fundamental limit of nanophotonic light trapping in solar cells, PNAS USA 107 (2010) 17491-17496.

[19] Z. Yu, A. Raman, S. Fan, Fundamental limit of light trapping in grating structures, Opt. Express 18 (2010) A366-A380.

[20] A. Mihi, F.J. Beck, T. Lasanta, A.K. Rath, G. Konstantatos, Imprinted electrodes for enhanced light trapping in solution processed solar cells, Adv. Mater. 26 (2014) 443-448. 
[21] C. Battaglia, C.M. Hsu, K. Söderström, J. Escarré, F.J. Haug, M. Charrière, M. Boccard, M. Despeisse, D.T. L. Alexander, M. Cantoni, Y. Cui, C.Ballif, Light trapping in solar cells: Can periodic beat random?, ACS Nano 6 (2012) 2790-2797.

[22] M. Niggemann, M. Glatthaar, P. Lewer, C. Müller, J. Wagner, A. Gombert, Functional microprism substrate for organic solar cells, Thin Solid Films 511-512 (2006) 628-633.

[23] R.M. Howden, E.J. Flores, V. Bulović, K.K. Gleason, The application of oxidative chemical vapor deposited (oCVD) PEDOT to textured and non-planar photovoltaic device geometries for enhanced light trapping, Org. Electron. 14 (2013) 2257-2268.

[24] Z. Hu, J. Zhang, Y. Zhao, Effect of textured electrodes with light-trapping on performance of polymer solar cells, J. Appl. Phys. 111 (2012) 104516-104522.

[25] J. Xu, Z. Hu, K. Zhang, L. Huang, J. Zhang, Y. Zhu, Enhancement in photocurrent via efficient geometrical light trapping in organic photovoltaics, Energy Technology, 4 (2016) $214-318$.

[26] Y.C. Chao, F.M. Zhan, H.D. Lia, Indium-tin-oxide nanorods for efficient light trapping in polymer solar cells, RSC Adv. 4 (2014) 30881-30886.

[27] S.W. Cho, Y.T. Kim, W.H. Shim, S.Y. Park, K.D. Kim, H.O. Seo, N.K. Dey, J.H. Lim, Y. Jeong, K.H. Lee, Y.D. Kim, D. C.Lim, Influence of surface roughness of aluminum-doped zinc oxide buffer layers on the performance of inverted organic solar cells, Appl. Phys. Lett. 98 (2011) $023102-023104$.

[28] L.M. Meskamp, Y.H. Kim, T. Roch, S. Hofmann, R. Scholz, S. Eckardt, K. Leo, A.F. Lasagni, Efficiency enhancement of organic solar cells by fabricating periodic surface textures using direct laser interference patterning, Adv. Mater. 24 (2012) 906-910. 
[29] J. Wang, S. Venkataraj, C. Battaglia, P. Vayalakkara, A.G. Aberle, Analysis of optical and morphological properties of aluminium induced texture glass superstrates, Jap. J. Appl. Phys. 51 (2012) 10NB08-10NB14.

[30] M. Berginski, J. Hüpkes, M. Schulte, G. Schöpe, H. Stiebig, B. Rech, M. Wuttig, The effect of front $\mathrm{ZnO}$ :Al surface texture and optical transparency on efficient light trapping in silicon thin-film solar cells, J. Appl. Phys. 101 (2007) 074903-074911.

[31] F. Yang, S.R. Forrest, Organic solar cells using transparent $\mathrm{SnO}_{2}-\mathrm{F}$ anodes, Adv. Mater. 18 (2006) 2018-2022.

[32] G. Yu, J. Gao, J.C. Hummelen, F. Wudl, A.J. Heeger, Polymer photovoltaic cells: enhanced efficiencies via a network of internal donor-acceptor heterojunctions, Science 270 (1995) 1789-1791.

[33] Y.G. Bi, J. Feng, Y. Chen, Y.S. Liu, X.L. Zhang, Y.F. Li, M. Xu., Y.F. Liu, X.C. Han, H.B. Sun, Dual-periodic-corrugation-induced broadband light absorption enhancement in organic solar cells, Org. Electron. 27 (2015) 167-172.

[34] J.Y. Kim, S.H. Kim, H.H. Lee, K. Lee, W. Ma, X. Gong, A. J. Heeger, New architecture for high-efficiency polymer photovoltaic cells using solution-based titanium oxide as an optical spacer, Adv. Mater. 18 (2006) 572-576.

[35] J.W. Leem, S. Kim, S.H. Lee, J.A. Rogers, E. Kim, J.S. Yu, Efficiency enhancement of organic solar cells using hydrophobic antireflective inverted moth-eye nanopatterned PDMS films, Adv. Energy Mater. 4 (2014) 1301315-1301321.

[36] J.H. Lee, D.W. Kim, H. Jang, J.K. Choi, J. Geng, J.W. Jung, S.C. Yoon, H.T. Jung, Enhanced solar-cell efficiency in bulk-heterojunction polymer systems obtained by nanoimprinting with 
commercially available AAO membrane filters, Small 5 (2009) 2139-2143.

[37] H. Sai, H. Jia, M. Kondo, Impact of front and rear texture of thin-film microcrystalline silicon solar cells on their light trapping properties, J. Appl. Phys. 108 (2010) 044505-044509. 


\section{Table captions}

\section{Table 1. The RMS roughnesses of all films are collected.}

\section{Figure captions}

Figure 1. Evolved AFM micrographs of AZO films textured with different etching time, (a) $0 \mathrm{~s}$, (b) $10 \mathrm{~s}$, (c) $30 \mathrm{~s}$ and the corresponding surface height-profile of AZO films (d).

Figure 2. (a)Total transmittance and haze spectrum of textured AZO films under various etching time, (b) total transmittance and haze spectrum of PEDOT:PSS/AZO substrates.

Figure 3. Surface depth distribution derived from AFM measurements for textured AZO films under various etching time.

Figure 4. AFM images of PEDOT:PSS films on textured AZO films under etching for $10 \mathrm{~s} \mathrm{(a),}$ and $30 \mathrm{~s}$ (c), and P3HT:PCBM on the corresponding PEDOT:PSS films for $10 \mathrm{~s}(\mathrm{~b})$, and $30 \mathrm{~s}$ (d). Figure. 5. Evolved surface height-profile from AZO films to P3HT:PCBM films for the etched samples for $10 \mathrm{~s}(\mathrm{a}), 30 \mathrm{~s}(\mathrm{~b})$.

Figure 6. SEM cross section of PSCs with rough substrates etched for $10 \mathrm{~s}$ (a), and $30 \mathrm{~s}$ (c),

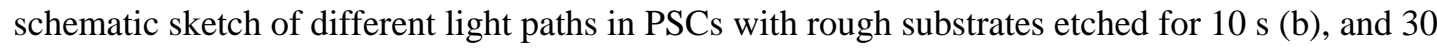
$s(d)$.

Figure 7. Summary of $V_{o c}, \mathrm{FF}, J_{s c}$, and PCE of the devices with the increased etching time.

Figure 8. Surface depth distribution derived from AFM measurements for films coated on textured substrates etched for $10 \mathrm{~s}(\mathrm{a})$, and $30 \mathrm{~s}(\mathrm{~b})$.

Figure 9. (a) Absorption spectra of active layers on different textured substrates, (b) total spectral reflection measured at normal incidence and (c) external quantum efficiency for devices based on the etched samples for $0 \mathrm{~s}, 10 \mathrm{~s}, 20 \mathrm{~s}, 30 \mathrm{~s}$ and $40 \mathrm{~s}$. 
Table 1. The RMS roughnesses of all films are collected.

\begin{tabular}{cccccc}
\hline Samples & RMS & RMS & RMS & RMS & RMS \\
& $(0 \mathrm{~s})$ & $(10 \mathrm{~s})$ & $(20 \mathrm{~s})$ & $(30 \mathrm{~s})$ & $(40 \mathrm{~s})$ \\
\hline AZO & $10.5 \mathrm{~nm}$ & $63.6 \mathrm{~nm}$ & $81.2 \mathrm{~nm}$ & $89.4 \mathrm{~nm}$ & $98.2 \mathrm{~nm}$ \\
PEDOT:PSS/AZO & $6.5 \mathrm{~nm}$ & $40.6 \mathrm{~nm}$ & $46.9 \mathrm{~nm}$ & $62.2 \mathrm{~nm}$ & $72.5 \mathrm{~nm}$ \\
P3HT:PCBM/PEDOT:PSS/AZO & $10.7 \mathrm{~nm}$ & $12.9 \mathrm{~nm}$ & $23.6 \mathrm{~nm}$ & $26.7 \mathrm{~nm}$ & $27.5 \mathrm{~nm}$ \\
\hline
\end{tabular}




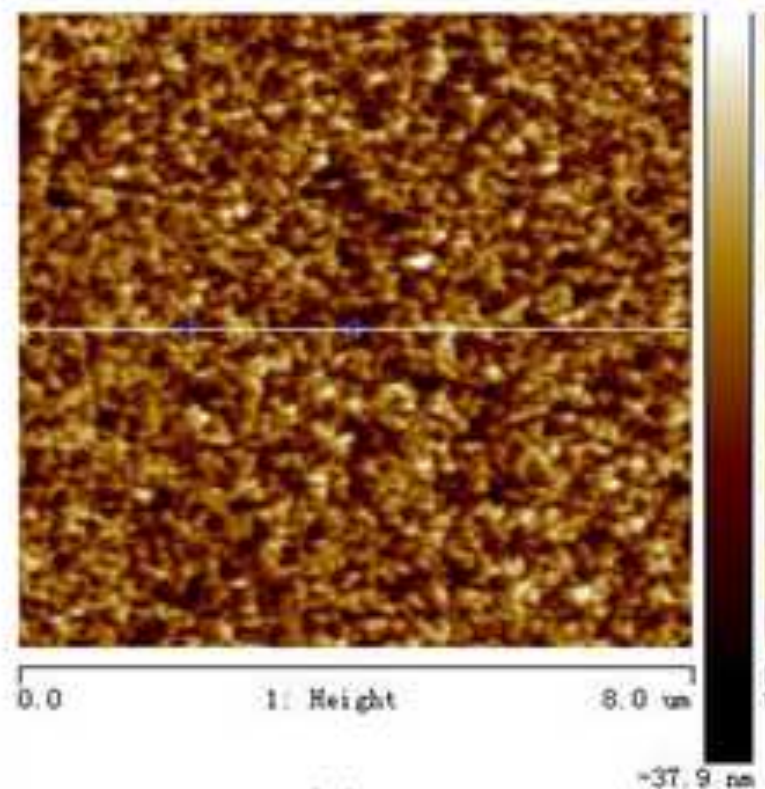

(a)

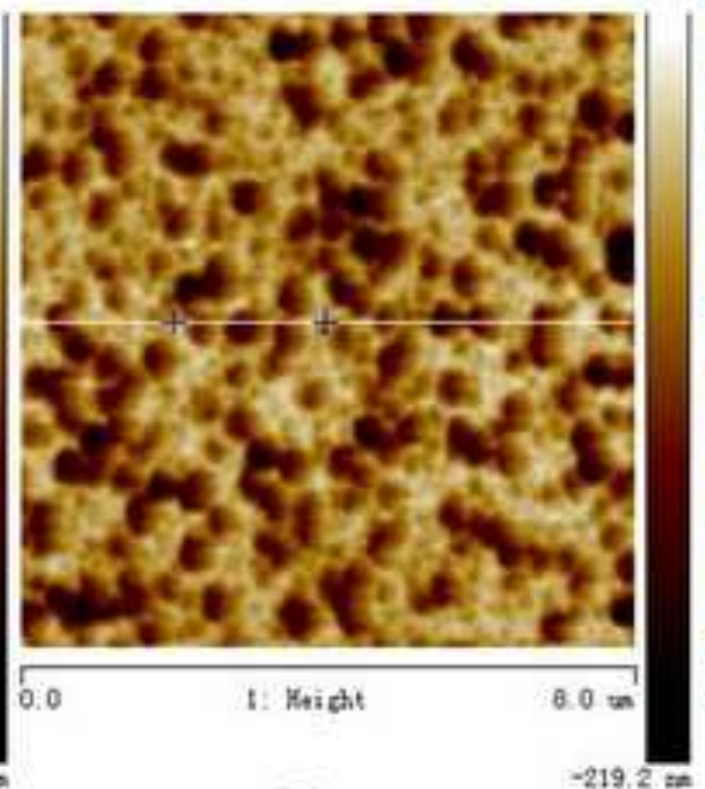

(b)

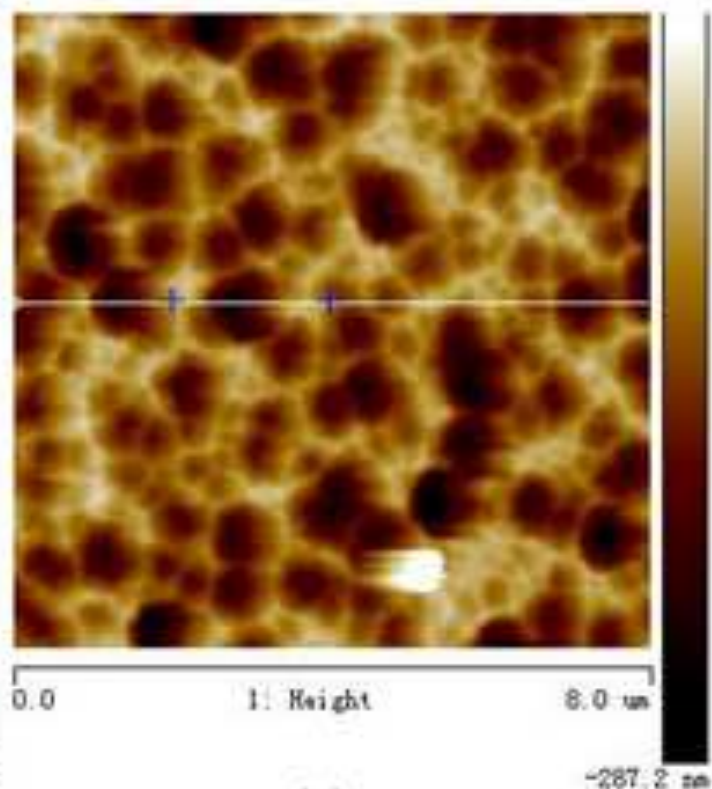

(c)

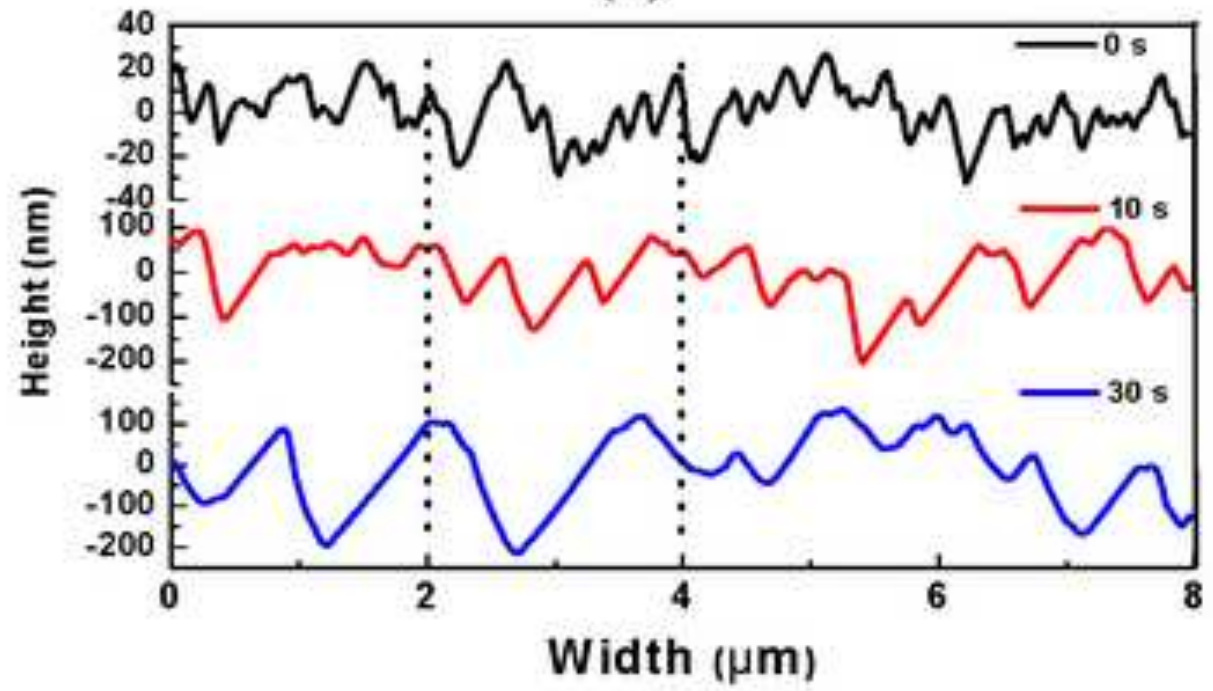

(d) 

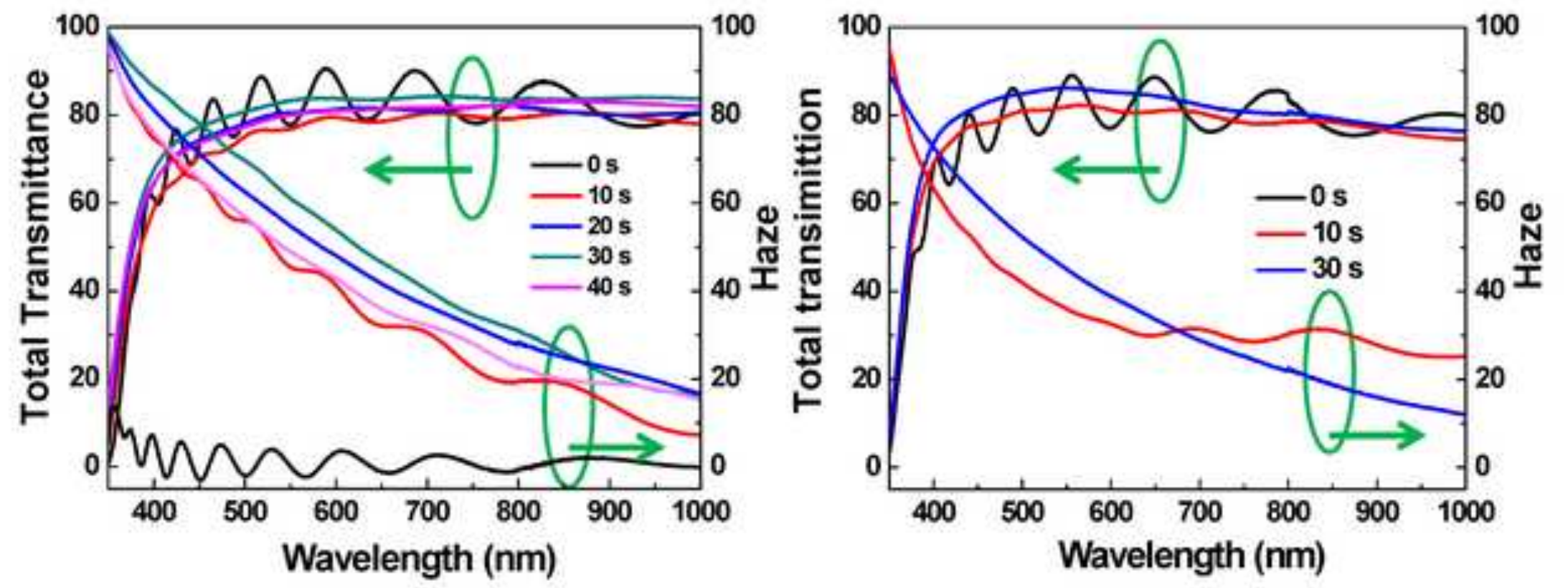


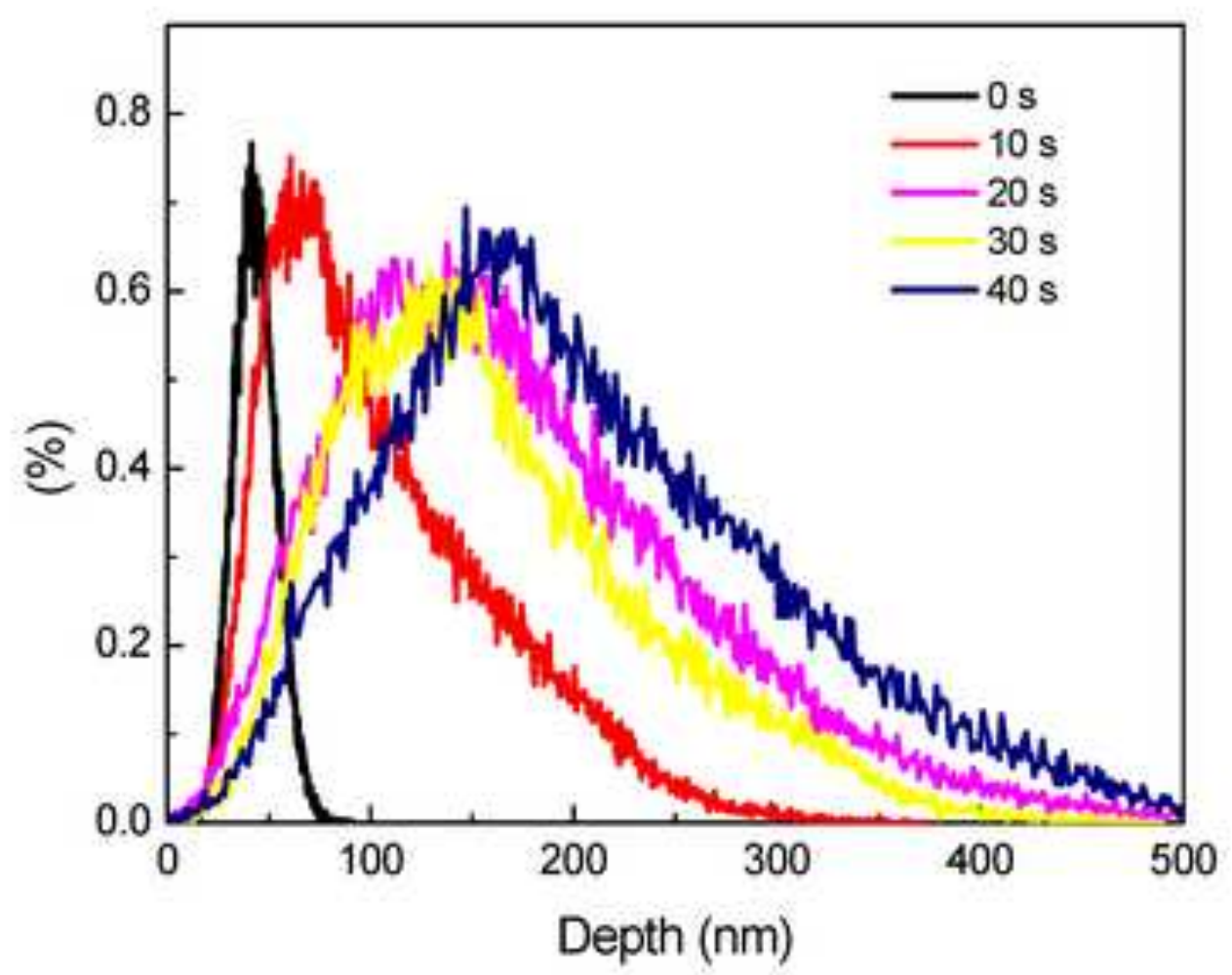



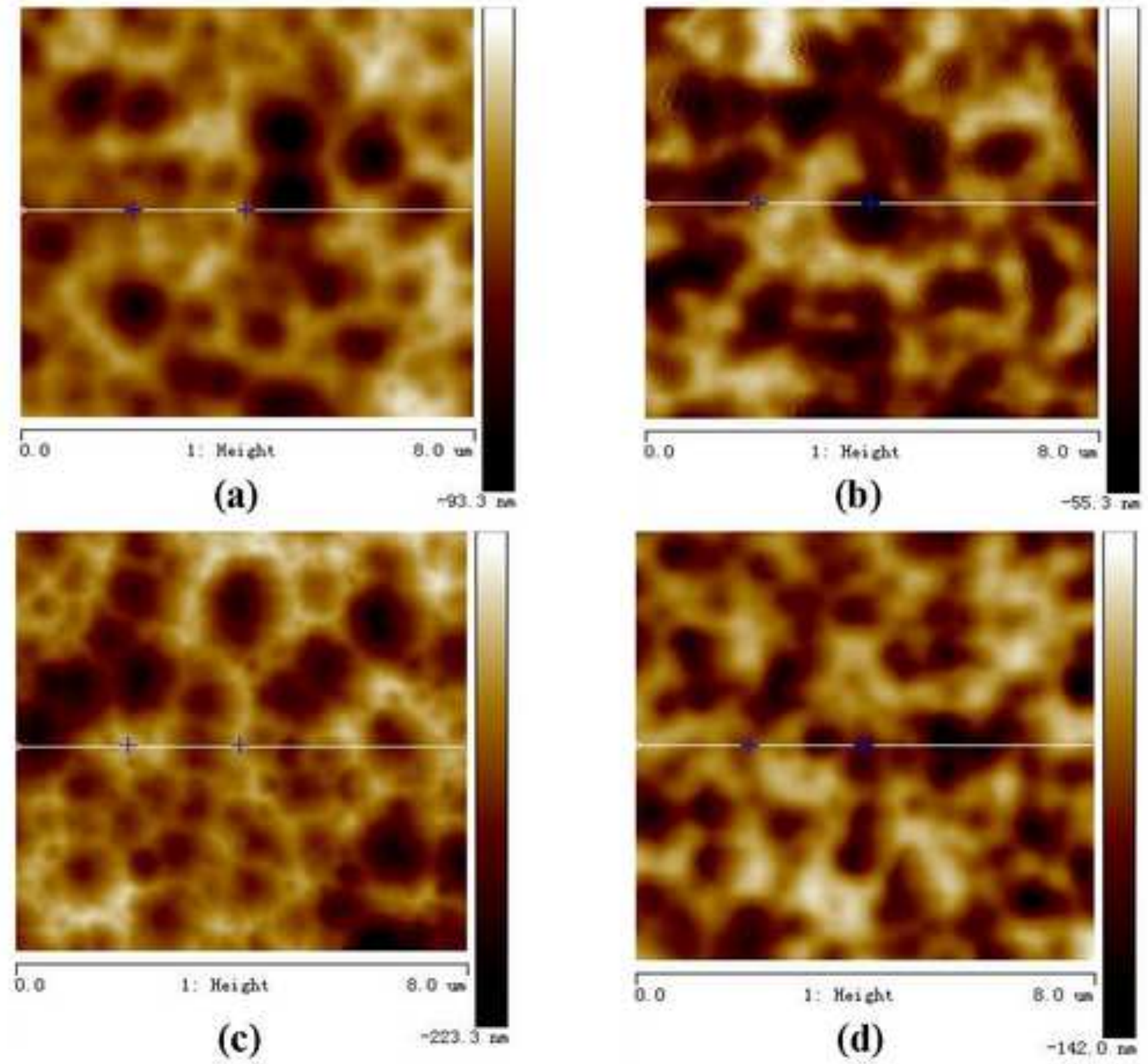

(c)

(d) 


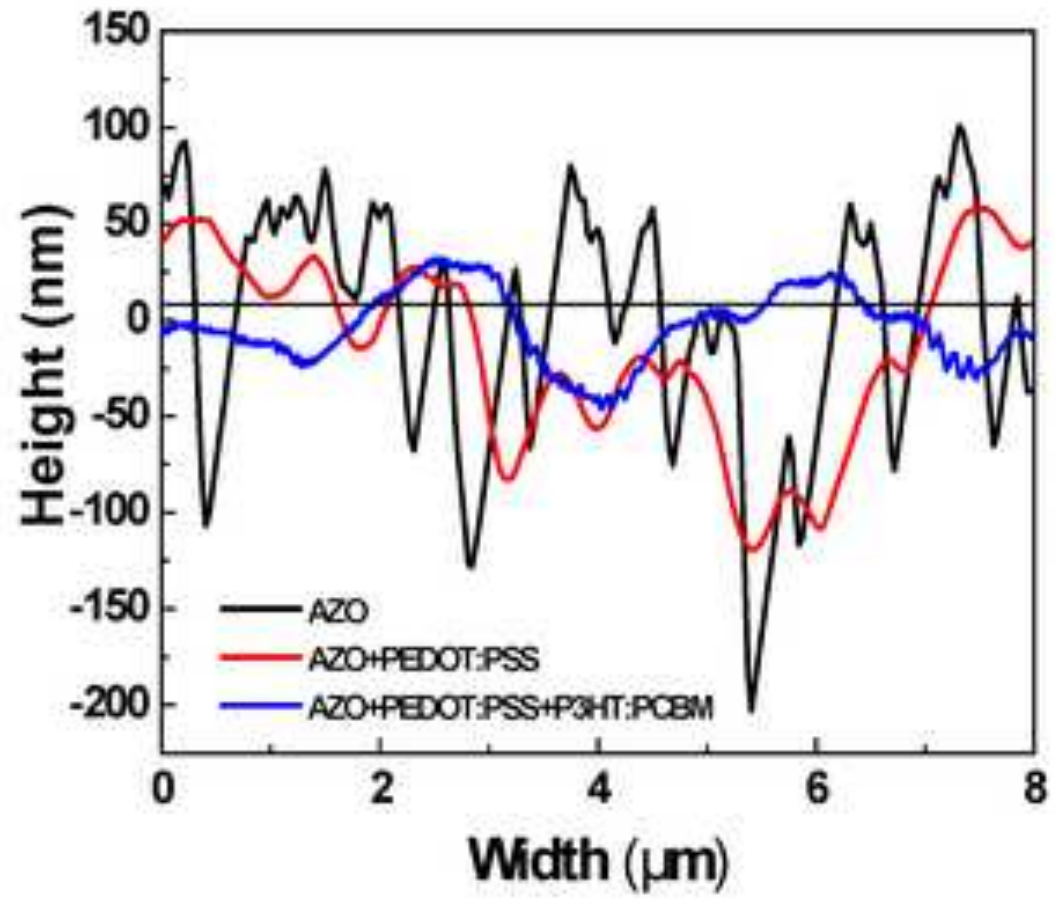

(a)

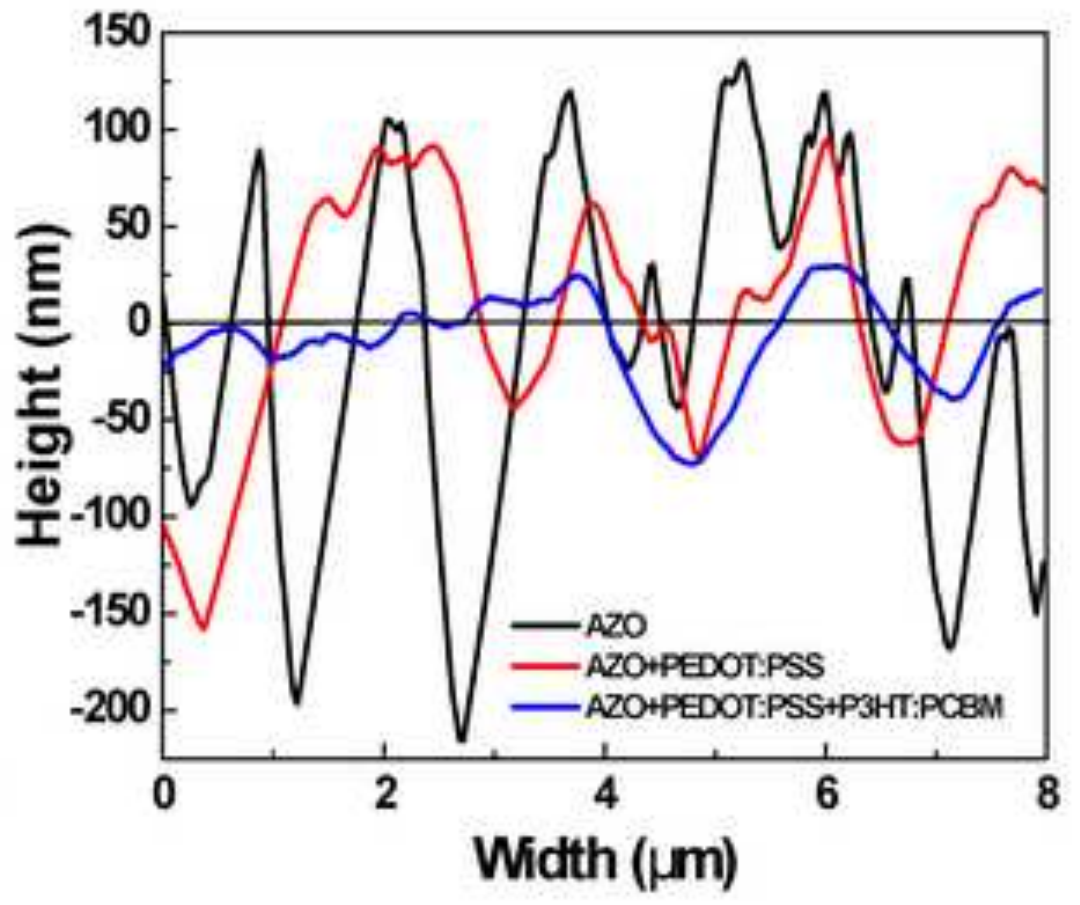

(b) 


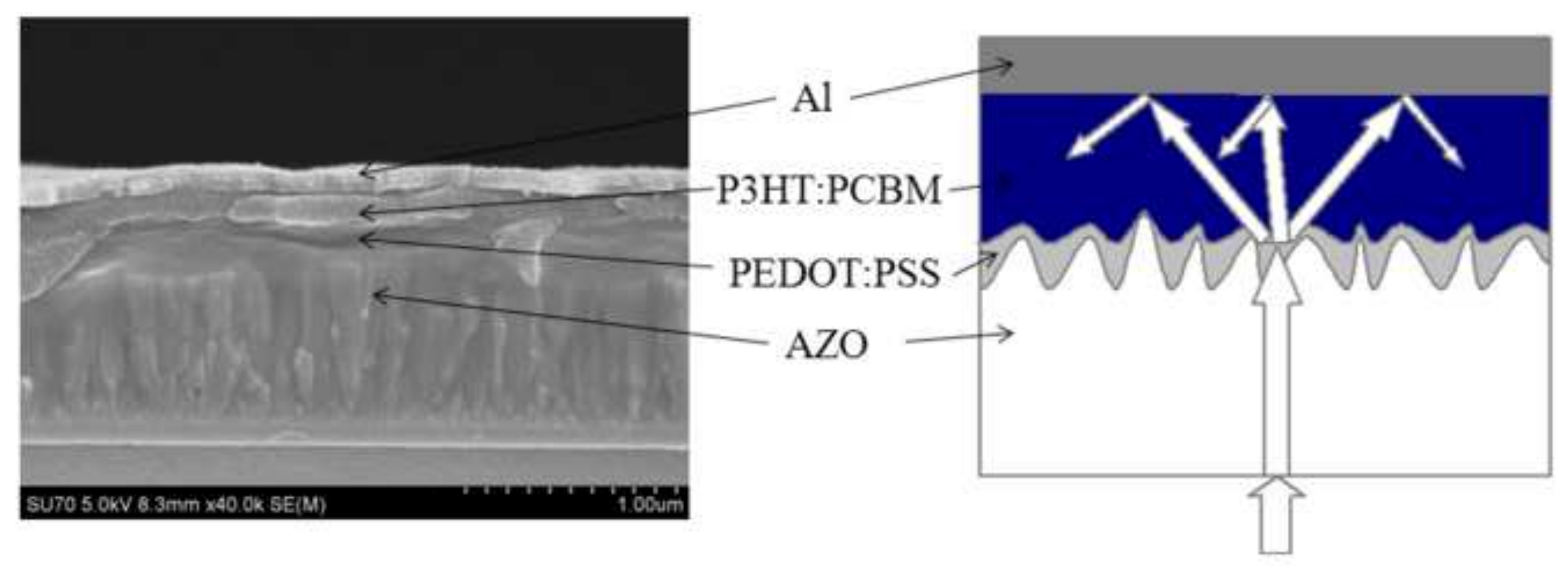

(a)

(b)

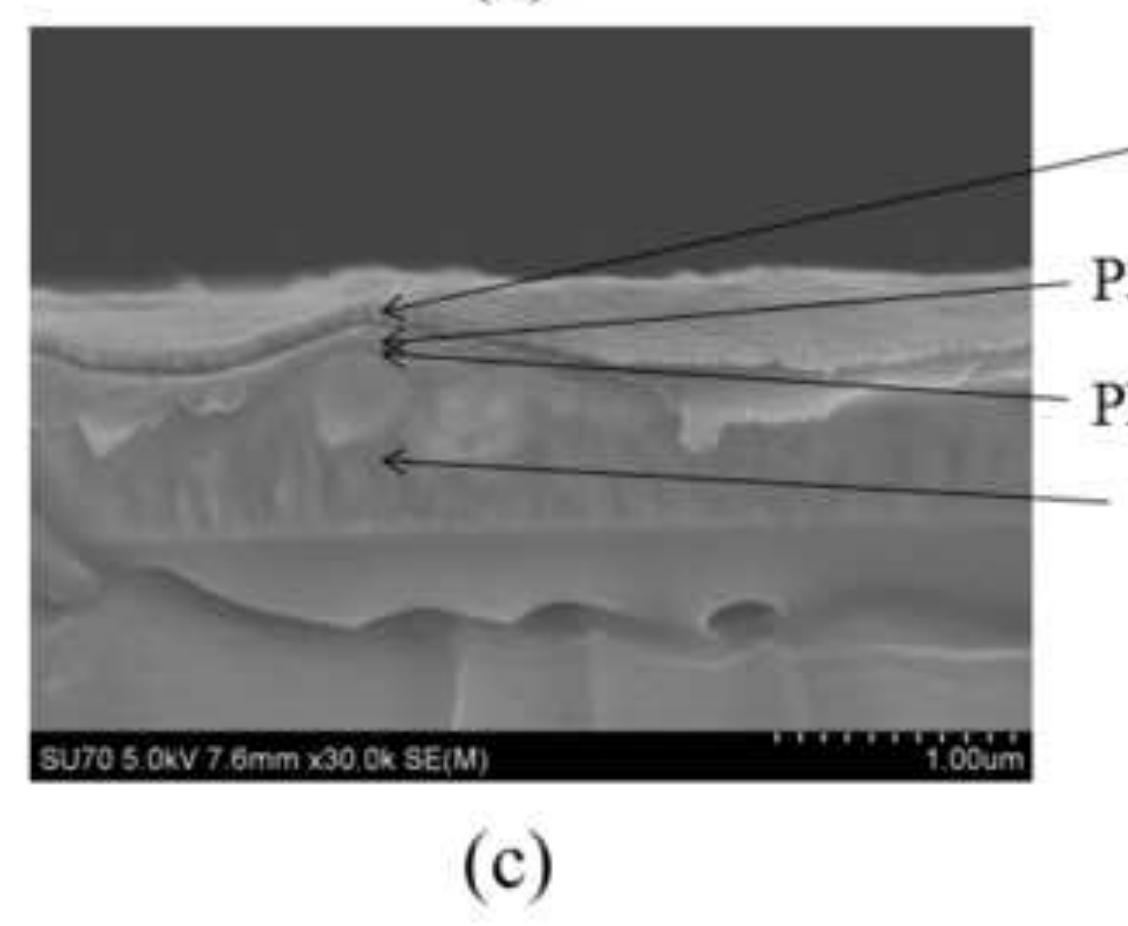

(c)

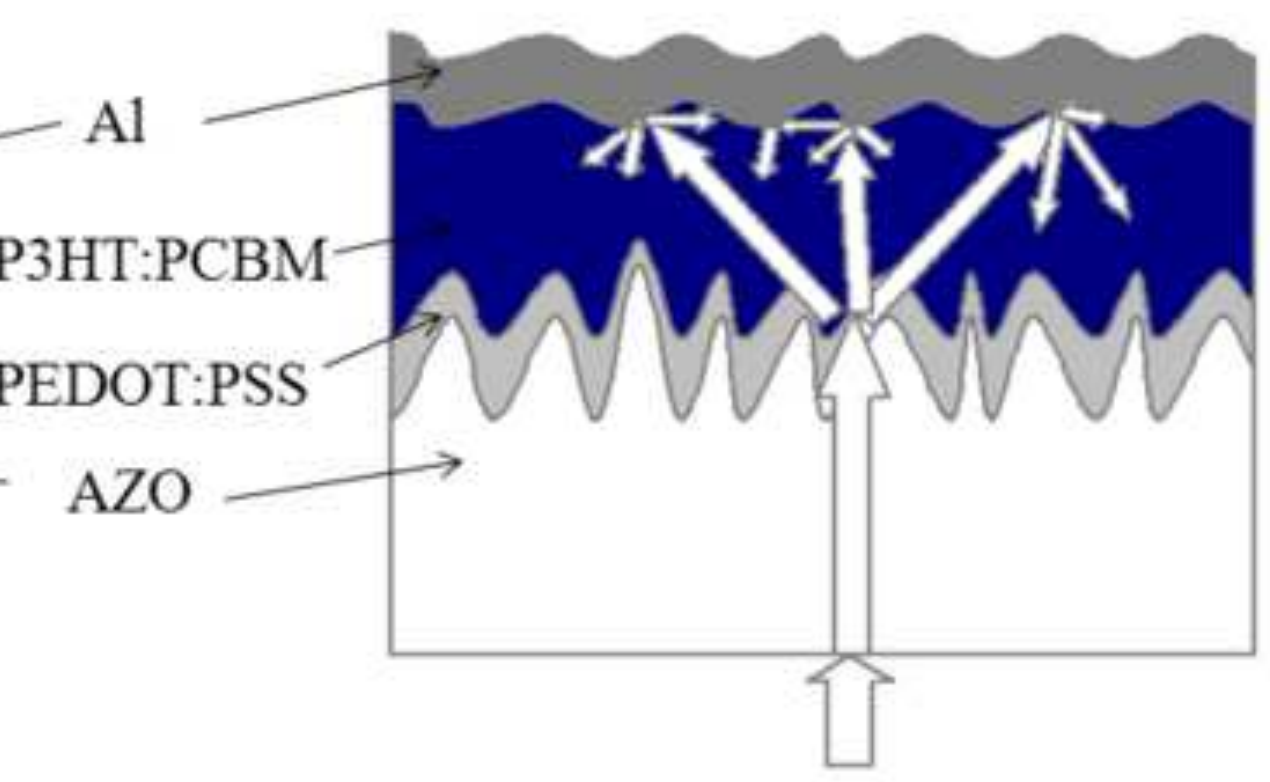

(d) 

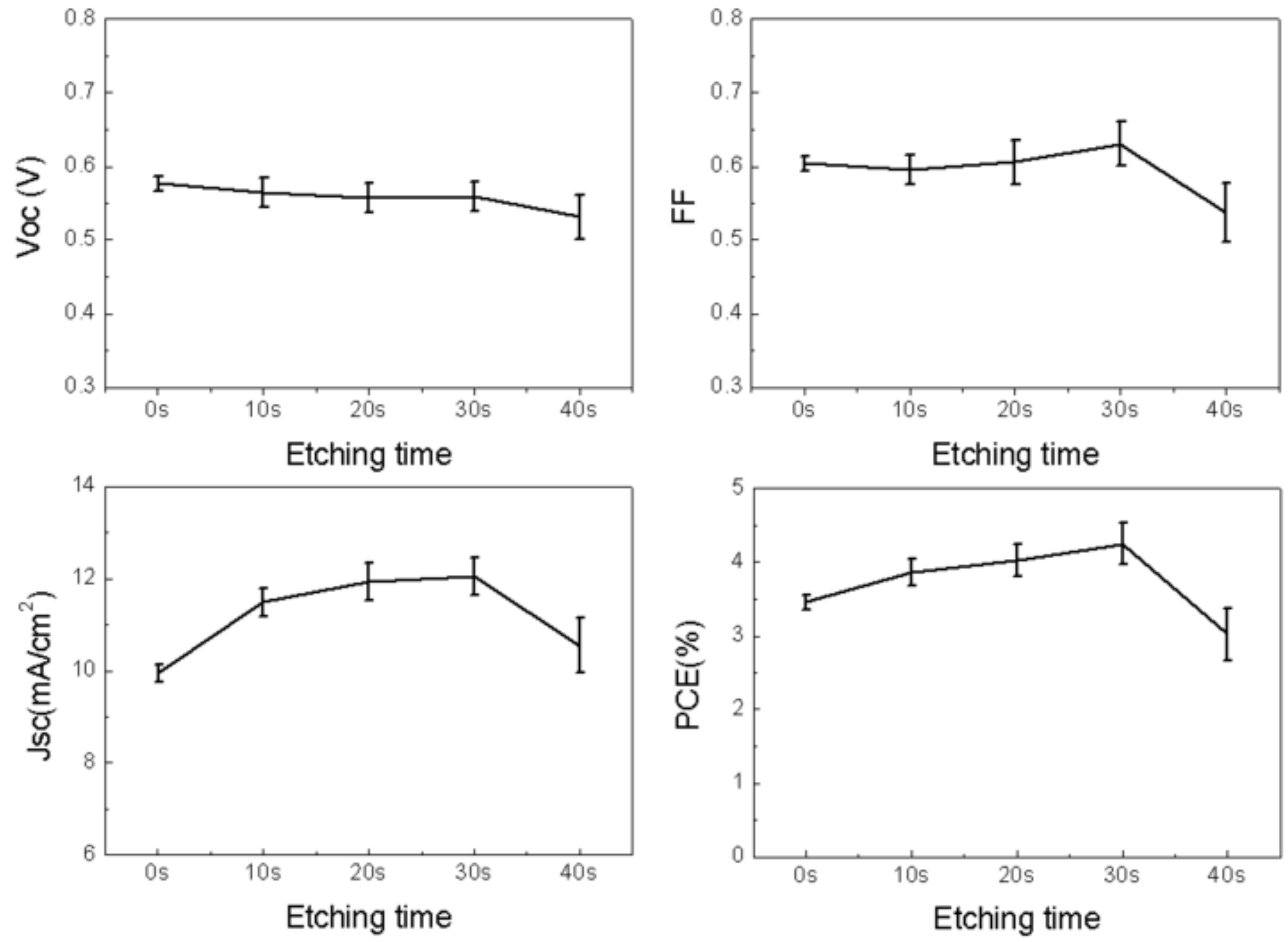


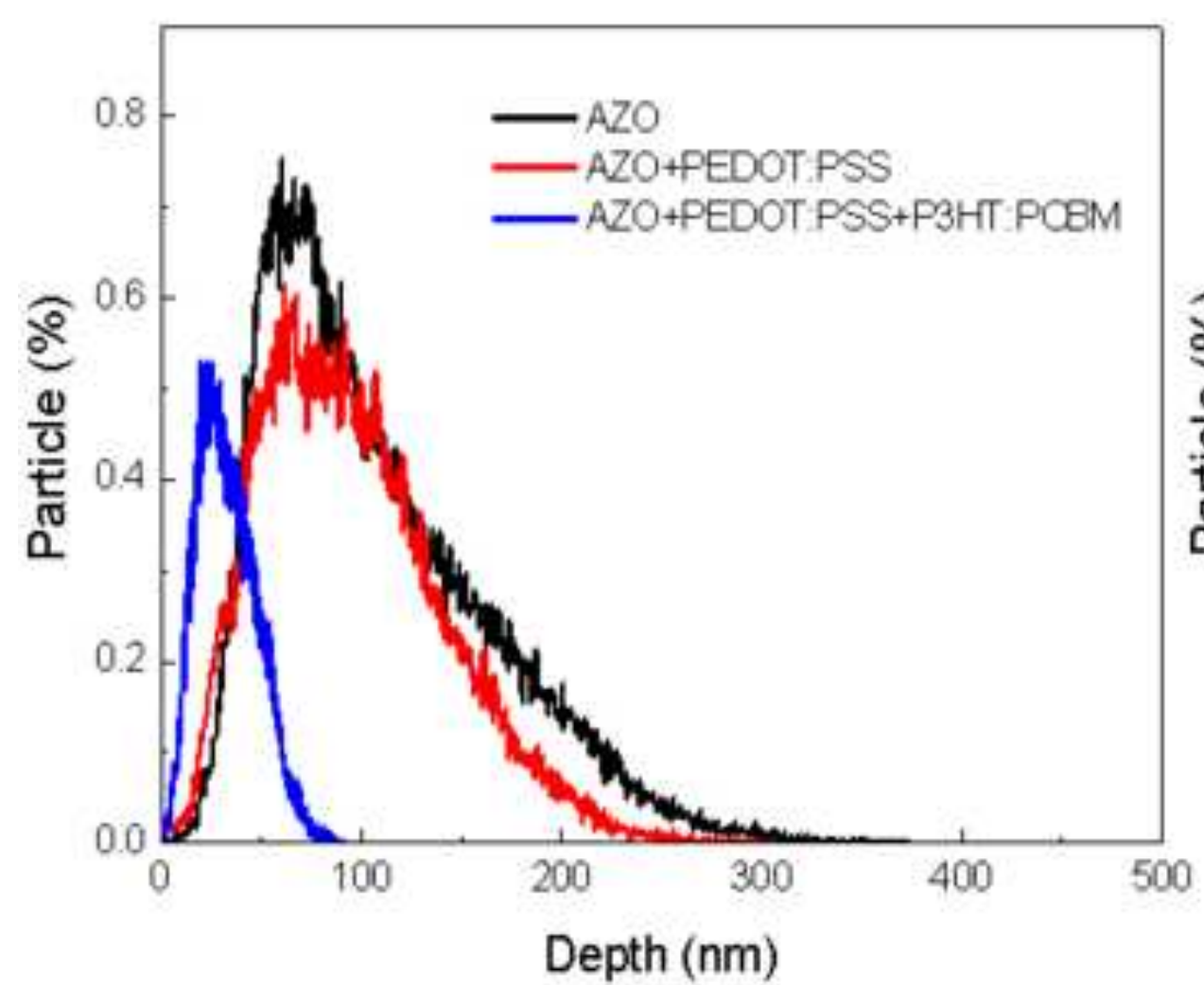

(a)

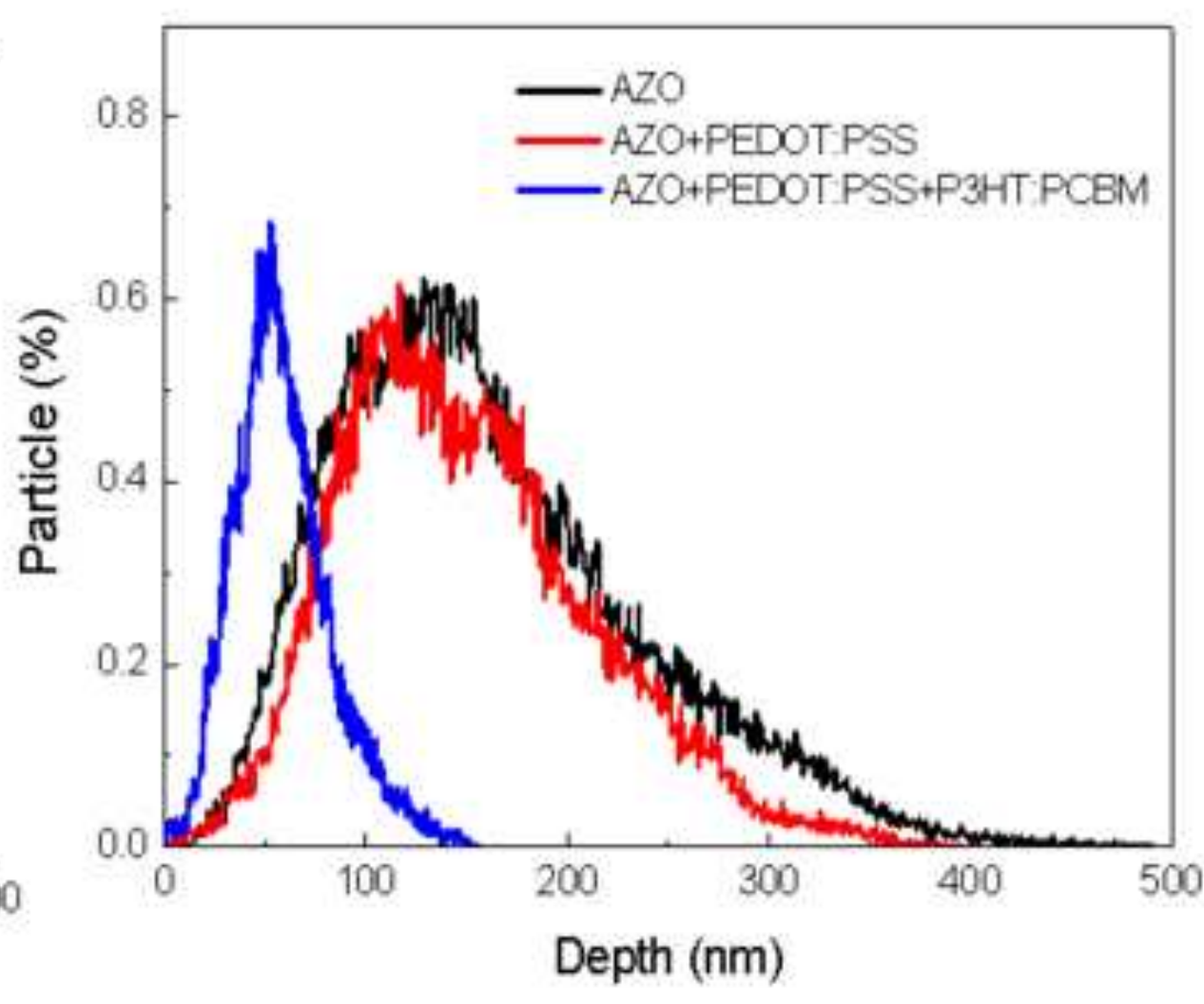

(b) 


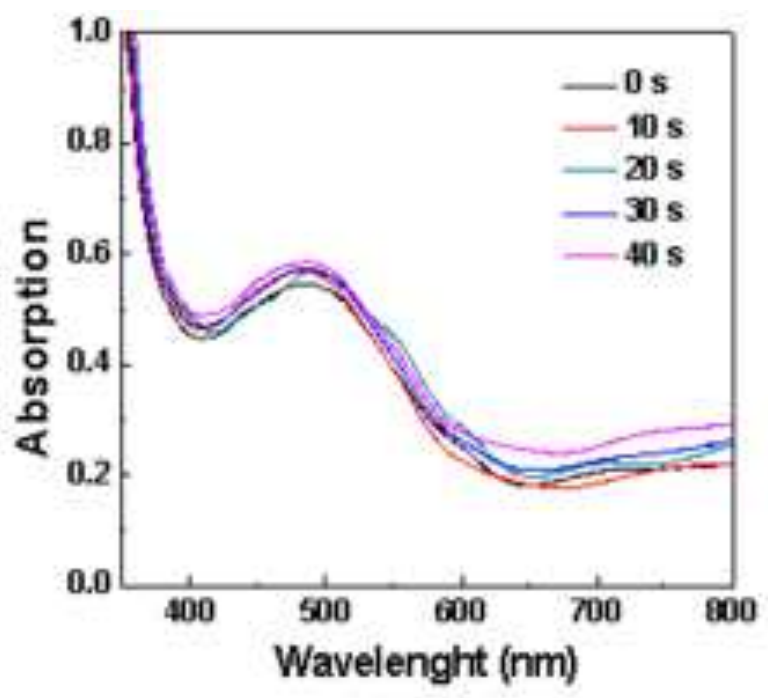

(a)

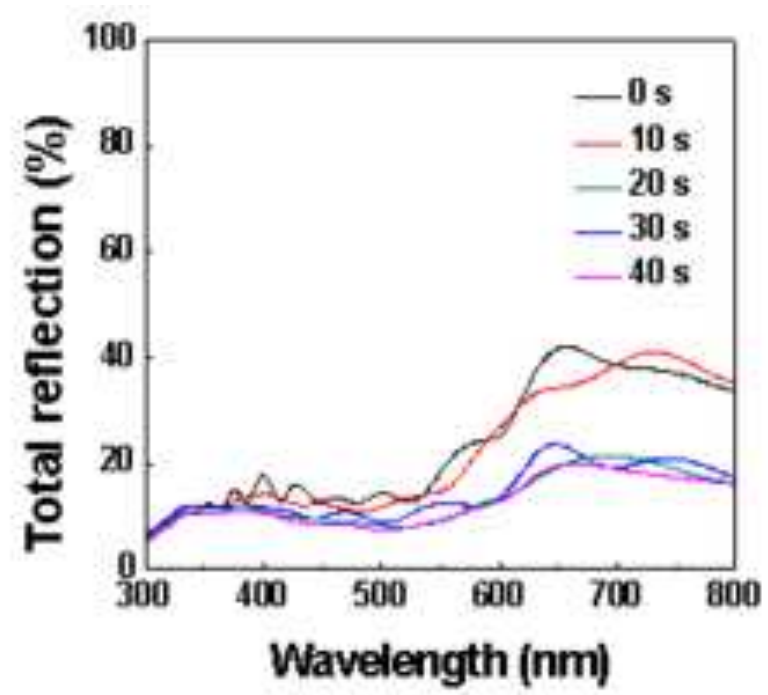

(b)

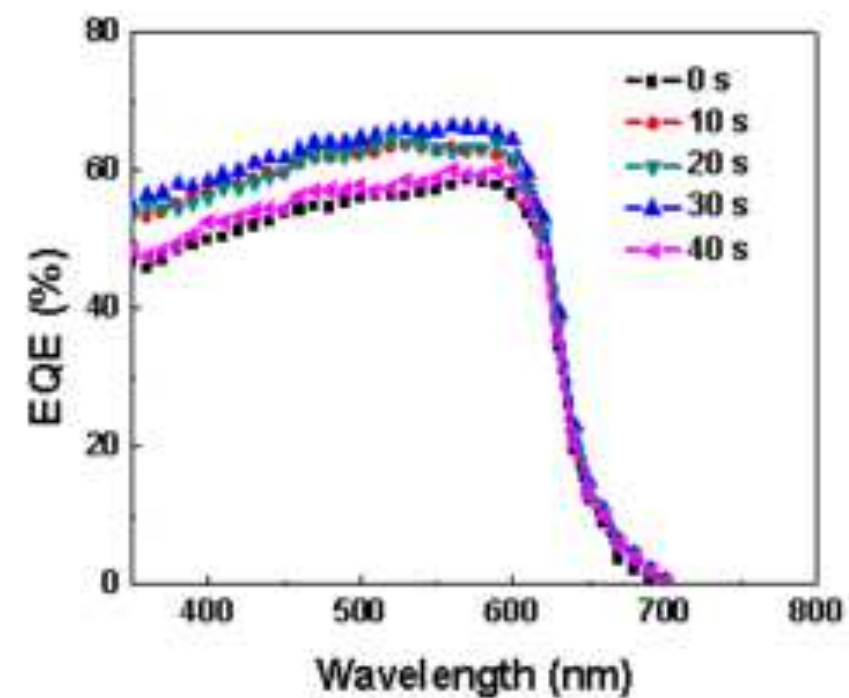

(c) 